Abant Tıp Dergisi

\section{Olgu Sunumu / Cilt 9 Sayı 3 YII 2020}

Abant Medical Journal

Case Report / Volume 9 Issue 3 Year 2020

\title{
Infantil Hemanjiomda Propranolol Tedavisi: Bir Olgu Sunumu
}

Propranolol Treatment in Infantile Hemangioma: A Case Report

Hatice Tuba AKBAYRAM ${ }^{1}$ iD, Ayse Ceyda ÖREN ${ }^{2}$

${ }^{1}$ Gaziantep Üniversitesi Tıp Fakültesi, Aile Hekimliği Anabilim Dalı, Gaziantep, Türkiye

${ }^{2}$ Gaziantep Üniversitesi Tıp Fakültesi, Çocuk Hematoloji Onkoloji Bilim Dalı, Gaziantep, Türkiye

\section{Öz}

İnfantil hemanjiom bebeklik döneminin en sık görülen vasküler selim tümörüdür. İnfantil hemanjiomun tedavisinde steroidler yıllardır ilk tercih olmakla birlikte son yıllarda oral propranolol de kullanılmaya başlanmıştır. Bu olgu ile eksremitelerinde hızlı büyüyen infantil hemanjiomu olan 1 aylık kız hastada birinci basamak tedavi olarak oral propranolol kullanımı sunulmuştur.

\section{Abstract}

Infantile hemangioma is the most common bening vascular tumors of infancy. Besides the steroids were the first choice in treatment of infantile hemangiomas for years, propranolol was also used in recent years. This study presents the use of oral propranolol as first-line therapy in a 1-month-old female patient with a fast growing infantile hemangioma in the exremites.

\section{Gíiş̧}

Hemanjiyomlar, bebeklerin \% 5-10'unu etkileyen en çok görülen vasküler benign tümörlerdir. Kızlarda üç kat daha fazla görülür. En çok baş ve boyun bölgesi olmak üzere gövde ve extremitelerde de görülebilir (1). Patogenezi tam olarak anlaşılmamış olmakla birlikte kadın cinsiyet, prematürite, ikiz bebekler, ileri anne yaşı, beyaz ırk, plesanta anomalileri ile ilişkili olduğu bildirilmiştir (2). Kapiller damar endotel hücrelerinin anormal proliferasyonu ile tipik olarak doğumdan 3-4 hafta sonra hastalık ortaya çıkar. 6 ve 7. ayda zirve yapar (3). IH'ların çoğu küçüktür, kendiliğinden geriler ve tedavi gerektirmez. Derin lezyonlar 7-8 yaşlarına kadar devam edebilmesine rağmen, 4 yaşına kadar vakaların \% 90'ında regresyon tamamlanır (4). IH yaygın olarak baş, boyun ve gövdede bulunur, ancak ekstremiteler, omurga ve viseral organlar dahil vücudun hemen her yerinde meydana gelebilirler (5).
IH'ların yaklaşık \%10'u tedavi gerektirecek önemli morbidite ile ilişkilidir. Kanama, şekil bozukluğu, ülserasyona neden olabilir (6). Bazı durumlarda IH'lar hızlı bir şekilde büyüyebilir, doku ve organların işlevini bozabilir ve hatta hastaların yaşamlarını tehdit edebilir (7).

IH'ların tedavisinde medikal ve cerrahi yöntemler kullanılmaktadır. Medikal tedavinin hedefi tümör küçülmesini sağlamaktır bu amaçla steroidler sıklıkla kullanılmakla birlikte yan etkilerinden dolayı alternatif tedavi seçenekleri üzerinde de durulmaktadır. Propranolol ilk kez 2008 yılında Leaute ve Lebreze tarafından kutanöz hemanjiyomlu hastalarda kullanılmış ve oldukça etkili bulunmuştur (8).

$\mathrm{Bu}$ olgu yaşamın ilk aylarından itibaren bebeklerin tedavi ve takiplerini yapan aile hekimlerinin IH ile ilgili farkındalıklarını arttırmak, IH'lu bebeklerin ailelerini çocuk hematoloji bölümüne yönlendirilmelerinin önemine dikkat 
çekmek ve propranolol tedavisinin etkisini vurgulamak amacıyla sunulmuştur.

\section{OLGU}

Bir aylık kız hasta, doğuştan itibaren kollarında, bacaklarında fark edilen ve zamanla büyüklüğünde artış olan kırmızı renkli cilt lezyonları nedeni ile aile sağlığı merkezimize getirildi. Öz ve soy geçmişinde özellik yoktu. Fizik muayenesinde kollarında 6 adet en büyüğü 10×5 $\mathrm{mm}$ boyutlarında ciltten kabarık kırmızı renkli plak biçimli cilt lezyonları dışında anormal bulgusu yoktu (Resim 1).

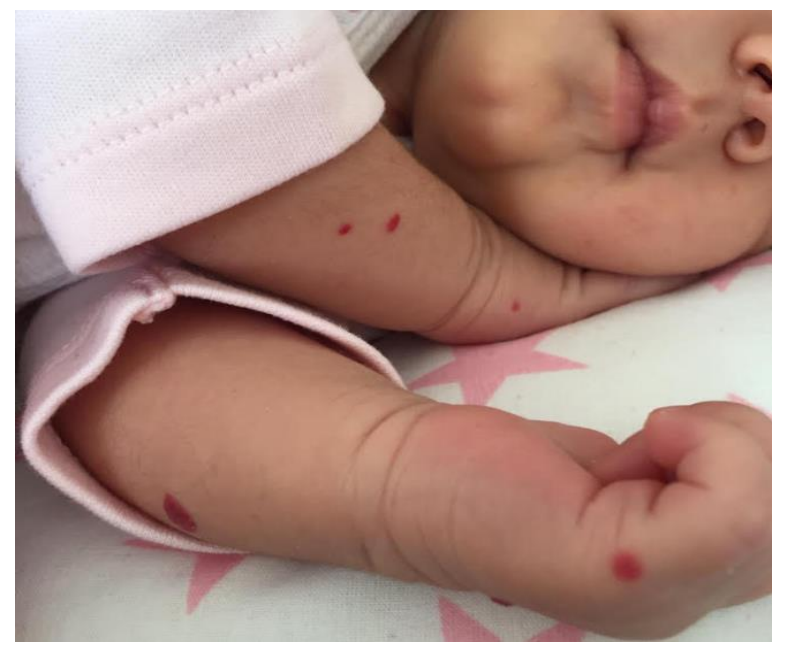

Resim 1.Her iki üst eksremitede hemanjiomlar

Hemanjiyom düşünülen hasta çocuk hematoloji polikliniğine yönlendirildi. Burada hastanın öykü ve fizik muayenesi ile IH tanısı ile değerlendirilen hastanın nabız ve kan basıncı değerleri normal bulundu. Eşlik edebilecek patolojiler açısından yapılan ekokardiografi, fontanel ve karın ultrasonografisi ise normal olarak değerlendirildi. Laboratuvar incelemesinde hemoglobin 12.3 $\mathrm{g} / \mathrm{dL}$, beyaz küre $6.900 / \mathrm{mm} 3$, trombosit $372.000 / \mathrm{mm} 3$, böbrek ve karaciğer fonksiyon testleri normaldi. Hastaya IH tanısı ile hastaya oral propranolol başlandı ( $1 \mathrm{mg} / \mathrm{kg} /$ gün, oral, iki bölünmüş dozda, 1 hafta). Hastanın vital bulguları ve kan değerleri takip edilerek doz kademeli olarak yükseltildi (2. hafta $2 \mathrm{mg} /$ $\mathrm{kg} /$ gün'e, 3. hafta $3 \mathrm{mg} / \mathrm{kg} /$ gün'e çıkıldı). $3 \mathrm{mg} / \mathrm{kg} / \mathrm{gün}$ 'la tedaviye devam edildi. Olası yan etkiler açısından (bradikardi, hipotansiyon, hipoglisemi, hiperkalemi) tedavinin ilk bir haftasında yakından takip edildi. Daha sonraki günlerde önce haftalık, daha sonra ayda bir kontrole çağııılarak takiplerine devam edildi. Bu dönemde lezyon renginde solma ve boyutlarında küçülme görüldü. Tedavinin 9. ayında tüm cilt lezyonları kaybolan hastanın (Resim 2) propranolol tedavisi kesildi ve bu süreçte herhangi bir ilaç yan etkisine rastlanmadı.

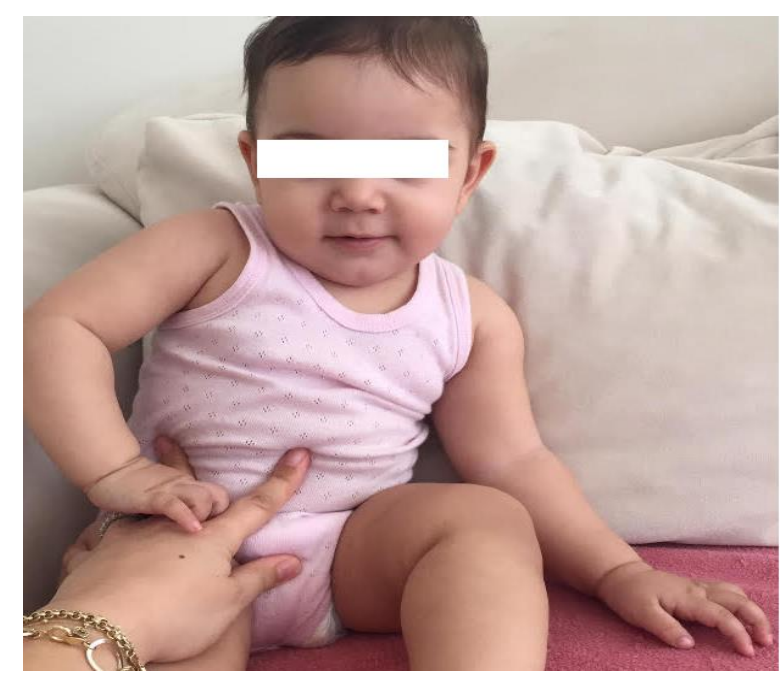

Resim 2.Tedavi sonrası hemanjiomlar düzelmiş

\section{TARTIŞMA}

Warfarin ï hayatın ilk yılında genellikle hızlı bir büyümenin ardından plato dönemine girer (9). Hızlı büyüme aşamasını regresyon ve stabilizasyon evreleri takip eder.10 IH'ların çoğu zamanla doğal olarak gerilese de, yaklaşık \%10$15^{\prime} \mathrm{i}$ ilgili uzman doktorlara sevk gerektiren komplikasyonlara neden olabilir (10). Bu nedenle risk altındaki hemanjiyomları erken tanımlamak ve tedavilerini yapmak çok önemlidir. IH'ın kadınlarda insidansı yüksektir. En fazla (\%80) baş ve boyun bölgesinde oluşurken gövde ve extremitelerde de görülebilir (3).

$\mathrm{Bu}$ olgumuzda, kız hastamızın her iki üst ekstremitesinde çok sayıda hemanjiom bulunmaktaydı. Aile tarafından hemanjiomların giderek büyümesi fark edilmişti. Hemanjiomların hoş olmayan görünümü ve ailenin estetik kaygısı tedavi için endikasyon sebebidir. IH'un büyüklüğü, derinliği, tutulum yeri, büyüme hızı ve 
kozmetik görünümü klinik açıdan değerlendirmede önemlidir.

Hemanjiomların medikal tedavisinde oral steroidlerin uzun süreli kullanımlarında ciddi yan etkileri nedeni ile alternatif olarak propranolol, IH tedavisinde 2008 yılından beri başarıyla kullanılmaktadır (8). Propranolol, ülser oluşturan, hayati yapıları olumsuz yönde etkileyen veya kozmetik sonuçları kötü olan karmaşık infantil hemanjiyomların bakım standardı haline gelmiştir. Biz bu olguda fizik muayene bulguları ve tetkikleri normal olan fakat kozmetik açıdan problem oluşturan hastada oral propranolol tedavisini tercih ettik. Propranololun yan etkileri arasında bradikardi, hipotansiyon, hipoglisemi ve bronkospazm sayılabilir. Kardiyak performansta azalmaya neden olabileceği için tedaviye başlamadan önce detaylı kardiyolojik muayene, elektrokardiyografi (EKG) ve ekokardiografik inceleme yapılması önerilmektedir (6). Bu olguda hastamızın tedavisine başlamadan ayrıntılı kardiyak muayene, EKG ve ekokardiyografisi yapıldı ve normal olarak değerlendirildi. Propranolol tedavisi sırasında hastanın kan basıncı, vital bulguları, kan glukoz değerleri ve kardiyak parametreleri takip edildi. İlacın herhangi bir yan etkisi görülmediği için kullanılması tercih edildi. Takip eden süreçte propranolol tedavisi ile lezyonların renk ve büyüklüklerinde gerileme olan hastanın tedavisi sekiz ay sürmüştür. Bu süre sonunda hastamızın hemanjiyomları tamamen kayboldu ve bu süreçte ilacın herhangi bir yan etkisi gözlenmedi.

\section{SONUÇ}

Bebeklik döneminde sık görülen $I^{\prime}{ }^{\prime} d a$ oral propranolol, komplikasyonları önlemek için mümkün olduğunca erken uygulanması gereken ilk basamak tedavidir. Bu olgu yaşamın ilk aylarından itibaren bebeklerin tedavi ve takiplerini yapan aile hekimlerinin IH ile ilgili farkındalıklarının artması, IH olan hasta bebeklerin ailelerini çocuk hematoloji bölümüne yönlendirilmelerinin önemini ve propranolol tedavisinin etkinliğini vurgulamak amacıyla sunulmuştur.

Bilgilendirilmiş Onam: Aileden sözlü onam alınmıştır.

Çıkar Çatışması: Yazarlar çıkar çatışması beyan etmemişlerdir.

Finansal Destek: Yazarlar finansal destek beyan etmemişlerdir.

\section{KAYNAKÇA}

1. Starkey E, Shahidullah H. Propranolol for infantile haemangiomas: a review. Arch Dis Child 2011; 96(9): 890-93.

2. Yang $\mathrm{H}, \mathrm{Hu} \mathrm{DL}$, Shu $\mathrm{Q}$, Guo XD. Efficacy and adverse effects of oral propranolol in infantile hemangioma: a meta-analysis of comparative studies. World J Pediatr 2019; 15: 546-58.

3. Kim J, Hong JW, Roh TS, Lee WJ. Oral propranolol therapy in 23 infants with infantile hemangioma. Arch Plast Surg 2018;45(6): 517-24.

4. Léauté-Labrèze $\mathrm{C}$, Harper $\mathrm{Jl}$, Hoeger $\mathrm{PH}$. Infantile haemangioma. Lancet 2017; 390 (10089): 85-94.

5. Chinnadurai $S$, Sathe NA, Surawicz T. Laser treatment of infantile hemangioma: A systematic review. Lasers Surg Med. 2016; 48(3): 221-33.

6. Ng M, Knuth C, Weisbrod C, Murthy A. Propranolol therapy for problematic infantile hemangioma. Ann Plast Surg 2016; 76 (3): 306-10.

7. Wang C, Li Y, Xiang B, Xiong F, Li K, Yang K, Chen S, Ji Y. Quality of life in children with infantile hemangioma: a case control study. Health Qual Life Outcomes 2017; 15(1): 221.

8. Leaute-Labreze $C$, Dumas de la Roque E, Hubiche $T$, Boralevi F, Thambo JB, Taieb A. Propranolol for severe hemangiomas of infancy. N Engl J Med 2008; 358: 2649-51.

9. Greenberger S, Bischoff J. Pathogenesis of infantile haemangioma. Brit J Dermatol 2013; 169: 12-9.

10. Aslan N, Arıkan E, Sivrice C, Ayata A. Propranolol ile Tedavi Edilen İnfantil Hemanjiyom: Bir Olgu Sunumu. Türkiye Çocuk Hast Derg 2015; 4: 278-279. 